\title{
Concentration profile of dissolved gas during hydrogen gas evolution: an optical approach
}

\section{$\operatorname{AUTHOR}(\mathrm{S})$ :}

Ando, Kota; Uchimoto, Yoshiharu; Nakajima, Takashi

\section{CITATION:}

Ando, Kota ... [et al]. Concentration profile of dissolved gas during hydrogen gas evolution: an optical approach. Chemical Communications 2020, 56(92): 14483-14486

\section{ISSUE DATE:}

2020-11-28

URL:

http://hdl.handle.net/2433/259427

\section{RIGHT:}

This is the accepted manuscript of the article, which has been published in final form at

https://doi.org/10.1039/DOCC05695B.; The full-text file will be made open to the public on 27 October 2021 in

accordance with publisher's 'Terms and Conditions for Self-Archiving'; この論文は出版社版でありません。引用の際に

は出版社版をご確認ざ利用ください。; This is not the published version. Please cite only the published version. 


\section{Concentration profile of dissolved gas during the hydrogen gas evolution: An optical approach}

Received 00th January 20xx,

Kota Ando, ${ }^{a}$ Yoshiharu Uchimoto, ${ }^{\text {b }}$ and Takashi Nakajima*a

Accepted 00th

DOI: $10.1039 / \times 0 \times x 00000 x$

We develop an optical image tracking technique for the simultaneous observation of wide area in proximity to the electrode, and study the growth of bubbles during the hydrogen gas evolution in alkaline water electrolysis. Using a diffusion model we can successfully extract the concentration profile of dissolved hydrogen gas as a function of distance from the electrode. Th obtained concentrations agree well with the values by the electrochemical method.

As one of the promising means to store renewable energy hydrogen evolution reaction through water electrolysis draws lot of interest in recent years. Although water electrolysis itself is a very classic method, achieving high efficiency for the practical purpose is not a trivial task. Finding efficient an durable electrocatalysts is obviously an important issue, and there are lots of related reports in the literature. ${ }^{1,2}$ Deep understanding of the nucleation process of bubbles on the electrode is another important issue from both practical and fundamental viewpoints. ${ }^{3-5}$ During electrolysis the concentration of the dissolved gas in close proximity to th electrode increases and reaches supersaturation, and depending on the supersaturation level a tiny local fluctuation most likely associated with local surface structures, triggers th nucleation of gas bubbles. Indeed, recent studies reveal that the nanobubbles are formed on the electrode through the so-called heterogeneous nucleation at the solid-liquid interface. ${ }^{3-6}$ Afte nucleation nanobubbles grow on the electrode in the supersaturated electrolyte, and when the buoyant force overcomes the adhesion force of growing bubbles to the electrode detachment of the bubble occurs. To many bubbles sticking on the electrode leads to the reduction of surface area,

\footnotetext{
Institute of Advanced Energy, Kyoto University, Gokasho, Uji, Kyoto 611-0011, Japan

E-mail: nakajima@iae.kyoto-u.ac.jp

Graduate School of Human and Environmental Studies, Kyoto University, Sakyoku, Kyoto 606-8501, Japan

Electronic Supplementary Information (ESI) available: optical image trackin analysis, Theoretical background, AFM data, movies]. See DOI: 10.1039/x0xx00000x
}

and hence early detachment of the bubble is favourable for the efficient electrolysis. The above scenario suggests that not only nucleation but also detachment of the bubbles is sensitive to the surface structure ${ }^{2,7}$ and wettability of the electrode. After detachment the bubbles further grow in the supersaturated electrolyte. ${ }^{8-11}$ of course, there is a concentration gradient of dissolved hydrogen gas, ${ }^{12}$ and up to what distance and size the bubbles can grow with what rates depends on the electrolysis conditions, and they play important roles toward the efficient hydrogen evolution. Note that the coalescence of bubbles can also occur on and in proximity to the electrode ${ }^{13}$ which further complicates the bubble dynamics.

Knowing all the above, it is reasonable to imagine that none of the sites on an ordinary electrode (i.e., without atomic flatness) behave exactly the same, and if so, a scanning electrochemical technique, ${ }^{12,14,15}$ which proves to be very powerful for the local study of nucleation and growth of bubbles on and in proximity to the electrode, would not be very appropriate to study the site-dependent behaviour of nucleation and detachment of bubbles, simply because the scanning technique is a one-site-at-one-time method and there is no way to compare the behaviours of two or more sites, at which, mainly due to the birth, growth, and detachment of the bubbles, the electrolysis processes are not stationary.

In this work we develop a new technique to investigate the growth of bubbles during the hydrogen gas evolution. It is baseb on the optical image tracking, with which we can the multiplesite-at-one-time measurements of hydrogen bubbles._Ou technique has a certain advantage over the one-site-at-onetime technique, since the electrolysis process is inherently nonstationary. Once the radii and the growth rates of the individud bubbles are experimentally obtained, by using the diffusion model, ${ }^{16}$ we can extract the concentration profile of the dissolved hydrogen in the electrolyte as a function of distance from the electrode. Our results are consistent with those obtained by the scanning electrochemical method. ${ }^{12}$

Fig. 1 shows the experimental setup. We employ an Ni wire $(99.9+\%, \phi 100 \mu \mathrm{m}$, Nilaco) as a working electrode without anly 


\section{COMMUNICATION}

(a) acrylic cuvette

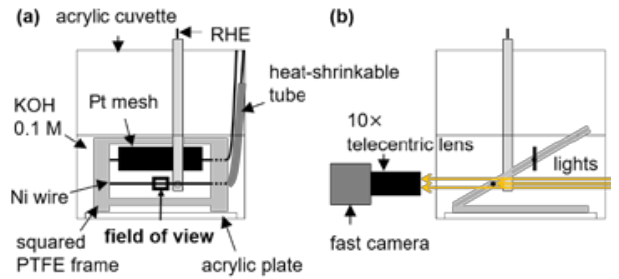

PTFE frame acrylic plate

\section{Fig. 1 Experimental setup.}

preprocessing. For the counter electrode we employ a Pt mesh (99.98\%, $26 \times 8 \mathrm{~mm}^{2}, \phi 120 \mu \mathrm{m}, 55 \mathrm{mesh} / \mathrm{inch}$, Nilaco) which is placed parallel to the $\mathrm{Ni}$ wire at a distance of $15 \mathrm{~mm}$. Both electrodes are fixed on a squared PTFE frame $\left(40 \times 40 \mathrm{~mm}^{2}\right.$ with a frame width of $5 \mathrm{~mm}$ ), and immersed in the $60 \mathrm{~mL} \mathrm{KOH}$ solution at $0.1 \mathrm{M}$ (FUJIFILM Wako Pure Chemical Co.) contained in an acrylic cuvette $\left(50 \times 50 \times 50 \mathrm{~mm}^{3}\right)$, as shown in Fig. 1a. The top of the cuvette is open to the air. As described in Fig. 1b, the working and counter electrodes are parallel but not at the equal height; the former is at the lower position to secure the clea view of hydrogen bubbles without the presence of oxygen bubbles. To expose the well-defined length of $\mathrm{Ni}$ wire to the $\mathrm{KOH}$ solution, the rest of the Ni wire which protrudes out of the PTFE frame is covered by a heat-shrinkable tube. As a result, the geometric surface area of the naked $\mathrm{Ni}$ wire is calculated to be $100 \mu \mathrm{m} \times \pi \times 3 \mathrm{~cm}=0.094 \mathrm{~cm}^{2}$. A reverse hydrogen electrode (RHE) is placed near the $\mathrm{Ni}$ wire to serve as a reference electrode. All the three electrodes are connected to potentiostat/galvanostat (HZ-7000, HOKUTO DENKO Co.). In this work we employ the constant-current mode for all the measurements, and the current is $-3,-5$, and $-8 \mathrm{~mA}$. Prior to the data acquisitions, the $\mathrm{Ni}$ wire electrode goes through the warm-up of $\sim 250$ s every time at the-current to be used for the following measurement. To observe bubbles we take their shadowgraphic images in proximity to the $\mathrm{Ni}$ wire electrode with a fast camera (CP70-1-M-1000, Optronis $\mathrm{GmbH}$, pixel size $6.6 \mu \mathrm{m}$ and $4000 \mathrm{fps}$ max for the resolution of $640 \times 480$ pixels under the LED illumination (AS3000, As One. Co.) through telecentric lens (ML 10x, Mitutoyo Co., NA 0.21 and depth of focus $6.2 \mu \mathrm{m}$ ). Accordingly, the field of view is $422 \times 317 \mu^{2}$. avoid motion blur the exposure time of the camera is set to 500 $\mu \mathrm{s}$. For each measurement, we take a movie for 0.1 second at the frame rate of 1000/s and store 101 frames in a PC, which are analyzed as we describe below.

For the image analysis we develop a home-made program based on the image analysis VIs installed in NI LabVIEW (NI). The program consists of three steps (Fig. S1, ESI+): (1) binarization of the raw images with an appropriate threshold value to preselect the candidates for bubbles, (2) evaluation of thei Heywood circularity factors (i.e., perimeter of the preselected image divided by the circumference of the circle with a sam area) to recognize the preselected candidate image as a bubble only if it is in the range of $1 \pm 0.03$, and (3) calculation of its growth rate through image tracking analysis of the bubbles.
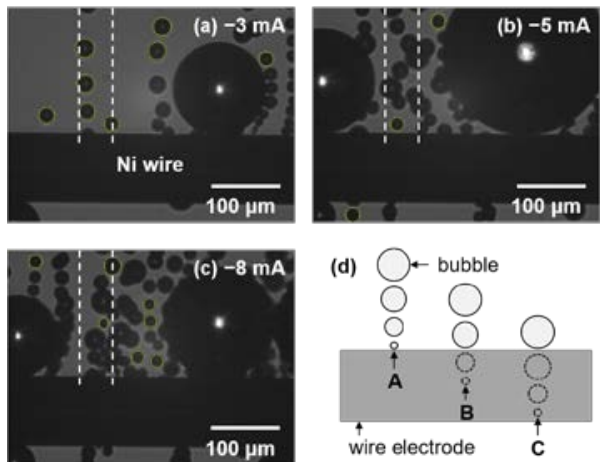

Fig. 2 Images of hydrogen gas bubbles in proximity to the Ni wire electrode at (a) -3 , (b) -5 , and (c) $-8 \mathrm{~mA}$, respectively. (d) Illustration of bubbles formed at three different sites on the wire electrode, shown as case A-C. The dashed circles in (d) represent the bubbles behind or at the front of the wire electrode.

Note that performing image tracking analysis, i.e., step (3), is the key to obtain the reliable growth rates of the bubbles.

It is very reasonable to assume that the bubbles in proximity to the electrode, typically less than a few hundred $\mu \mathrm{m}$ from the electrode, are well within the diffusion layer. Therefore, once we obtain the radii and growth rates of the respective bubbles in this region we can apply the simplified EP equation (Eq. (S2) $\mathrm{ESI}+$ ) to iteratively_extract the concentration profile.

Fig. 2 shows the hydrogen bubbles in proximity to the Ni wire electrode under the constant current mode at $-3,-5$, and -8 $\mathrm{mA}$, respectively, in which the bubbles that have been recognized as isolated bubbles through the image analysis described above are circled by yellow lines. Movies corresponding to Fig. 2(a)-(c) are also presented (movie S1-3, $\mathrm{ESI}+)^{)}$. Note that most of the bubbles detach the electrode when they grow up to the diameter of a few tens of $\mu \mathrm{m}$, while a few of them still stays on the electrode until their diameters reach 150 300 $\mu \mathrm{m}$. Interestingly, soon (within $\sim 0.01 \mathrm{~s}$ ) after a large bubble detaches the electrode a new bubble is born at the same site on the electrode, and this process is repeated. Comparison of Fig. 2(a)-(c) reveals that the number of such sites increases as the current increases (to the negative side). Motion of normalsize bubbles around a large bubble is irregular due to the loca convection, and they are sometimes attracted to the large one (movie S1-3, ESI+). Accordingly, normal-size bubbles near the large one cannot be used to evaluate the growth rate. A carefu examination of Fig. 2(a)-(c) reveals that there is a specific region on the wire where only normal-size bubbles appear under all the three current values, as indicated by the pairs of vertical dashed lines in Fig. 2(a)-(c). By further examining this region we notice that some of the bubbles show up from the upper horizontal boundary of the wire electrode with an already grown-up size, while others do not. A simple explanation for this puzzling observation is illustrated in Fig. 2(d). Clearly, the bubble
書式変更：蛍光ペン (なし)

書式変更：蛍光ペン (なし)

書式変更：蛍光ペン（なし）

書式変更：蛍光ペン（なし）

書式変更：蛍光ペン（なし）

書式変更：蛍光ペン (なし)

書式変更：蛍光ペン (なし)

書式変更：蛍光ペン (なし)

書式変更：蛍光ペン（なし）

書式変更：蛍光ペン（なし） 
(a) $-3 m A$
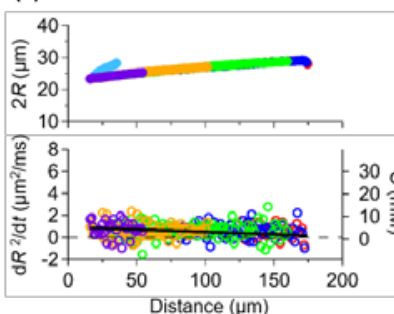

Distance ( $\mu \mathrm{m})$ (b) $-5 \mathrm{~mA}$
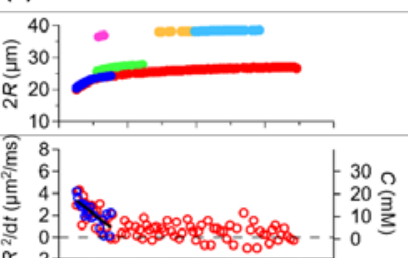

응

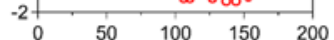

(c) $-8 \mathrm{~mA}$

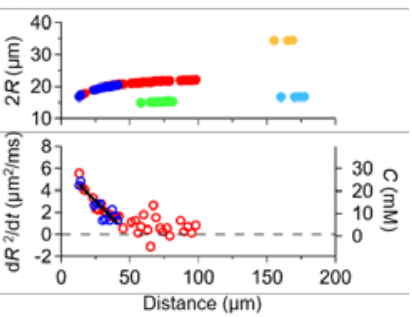

Fig. 3 Diameter (upper panel), $2 R$, and growth rate (lower panel), $\mathrm{d} R^{2} / \mathrm{d} t$, of detaching hydrogen bubbles from the electrode at the currents of (a) $-3,(b)-5$, and (c) $-8 \mathrm{~mA}$. Distance zero is chosen at the upper boundary of the wire electrode. As a result of tracking analysis of the bubble images, the data of the same bubbles are represented by the same colour. Solid black lines represent the results of linear fittings to the growth rates. Dissolved gas concentration, $C$, is also shown in the lower panels.

that is most ideal for the measurement of bubble growth is case A in Fig. 2(d)

After applying step (1)-(3) to the bubbles in the region between the two vertical dashed lines in Fig. 2 (and for all frames in movie S1-3, ESIt), we obtain the variation of bubble diameter, $2 R$ (upper panels of Fig. 3(a)-(c)), as a function of distance from the $\mathrm{Ni}$ wire electrode under the different currents. At the current of $-3 \mathrm{~mA}$ (upper panel of Fig. 3(a)) five bubbles out of six (other than the one shown by cyan) show the similar behaviour, and those five bubbles have been successively produced at the same site on the electrode $\left(\right.$ movie $\left.\mathrm{S}_{1, \mathrm{ESI}} \mathrm{t}\right)$. We point out that very similar behaviour of bubble diameter change (as a function of distance from the electrode) associated with the same site implies that the concentration profile of the dissolved gas on and in proximity to this site remains practically the same. Similar argument holds for the two bubbles (red and blue ones) shown in the upper panels of Fig. 3(b) and (c) at the currents of -5 and $-8 \mathrm{~mA}$, for which we evaluate the bubble growth rates. The lower panels of Fig. 3(a)-(c) represent the growth rates, $\mathrm{d} R^{2} / \mathrm{d} t$, of the bubbles. It turns out that $\mathrm{d} R^{2} / \mathrm{d} t<<$ $\pi D \approx 12 \mu \mathrm{m}^{2} / \mathrm{ms}$ in all Fig. 3(a)-(c), and we confirm that the simplified EP equation (Eq. (S2), ESIt), is valid for our experiments. The growth rates obtained above can be converted into the concentration, $C$, by iteratively solving the simplified EP equation for $C$ at different distances from the electrode with $D=4.2 \mu \mathrm{m}^{2} / \mathrm{ms}, k_{\mathrm{H}}=0.78 \mathrm{mM} / \mathrm{atm}, P_{\mathrm{B}}=1 \mathrm{~atm}$ and $n_{B}=40.9 \mathrm{mM}_{.}^{9,17}$ Results are shown in the lower panels of Fig. 3 by neglecting the influence of Laplace pressure, since we find that its influence is well within the experimental errors.

When the bubbles are too close to the wire electrode we face the technical difficulty to isolate tiny bubbles from the electrode through the image analysis. Under the current experimental conditions, the closest distance for the measurement and image analysis is $\sim 15 \mu \mathrm{m}$ from the electrode. After performing the linear fittings to the concentration (lowe panels of Fig. 3(a)-(c)) and extrapolating the fitted lines to distance zero, we obtain the concentrations of dissolved hydrogen gas on the electrode to be $5.4 \pm 0.7,23.2 \pm 2.1$, and $30.9 \pm 1.8 \mathrm{mM}$ for the currents of $-3,-5$, and $-8 \mathrm{~mA}$, respectively. The concentration of dissolved hydrogen gas, $30.9 \pm 1.8 \mathrm{mM}$, we have obtained for the current of $-8 \mathrm{~mA}$ and hence curren density of $-85 \mathrm{~mA} / \mathrm{cm}^{2}$ agrees well with the one obtained by the scanning electrochemical method using a Pt microelectrode. ${ }^{12}$

From the horizontal intercept (i.e., distance axis in Fig. 3) d the fitted black line we can also estimate the so-called diffusion layer thicknesses, and they are $218 \pm 75,46.9 \pm 8.9$, and $48.7 \pm 5$. 5 $\mu \mathrm{m}$ for the currents of $-3,-5$, and $-8 \mathrm{~mA}$, respectively. Thus obtained diffusion layer thicknesses are also consistent with the reported results..$^{12}$ Reasonable agreement between our results by the optical image tracking method and those by the scanning electrochemical method ${ }^{12}$ gives us a confidence that our method is reliable. However, a mystery remains: Even the highest concentration of the dissolved hydrogen gas on the wire we have obtained, $30.9 \pm 1.8 \mathrm{mM}$ at the current density of -85 $\mathrm{mA} / \mathrm{cm}^{2}$, is still much smaller than that required for the hydrogen gas nucleation on a flat electrode, which is $\sim 200 \mathrm{mM}$. A most plausible explanation for this discrepancy is that the surface roughness of the electrode plays an important role. That is, our results seem to imply that not only the wire electrode we have employed in this work (with the average roughness of a few hundred nm measured by AFM (Fig. S2, ESI+)) but also th electrodes which are often referred to in the literature as mirror-finished would not be a good approximate to the ideally flat surface. This speculation also explains why we find a few favourable bubble forming sites on our wire electrode: Once a nanobubble has been formed for some reason and persistently stays there, it is relatively easy for the bubble to repeatedly grow at and depart from the site by leaving a persistent seed bubble on the same site, and this is the case of so-called type III or type IV nucleation processes as proposed by Galvin et al. ${ }^{18}$ We do not dare to go into this issue, since it is out of scope of this work. We emphasize once more that the simultaneous observation of the wide area in proximity to the wire electrode which is not possible if one uses a scanning electrochemica method, offers more information on nucleation and growth of bubbles on the different specific sites of the electrode during electrolysis.

Having studied the dissolved concentration of hydrogen gas in proximity to the $\mathrm{Ni}$ wire electrode, another important question is how the bubbles move away from the electrode
書式変更：フォント：斜体

書式変更：蛍光ペン（なし） 書式変更：フォント：斜体

書式変更：蛍光ペン (なし)

書式変更：蛍光ペン（なし）

書式変更：蛍光ペン (なし)

書式変更：蛍光ペン（なし） 


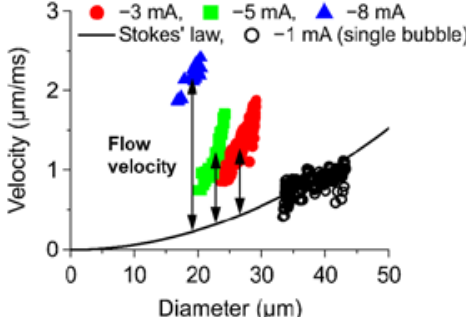

Fig. 4 Correlation of the rising velocity and diameter, $2 R$, of the bubbles generated at $-1,-3,-5$, and $-8 \mathrm{~mA}$. Solid black line represents the terminal velocity of the rising bubbles calculated by the Stokes' law. Flow velocities are also shown by arrows.

toward the electrolyte surface. More specifically our question is whether and how much the rising velocity of the bubbles depends on the employed current. Fig. 4 summarizes the correlation of diameter and rising velocity of the bubbles for the currents of $-1,3,-5$, and $-8 \mathrm{~mA}$ together with the theoretical velocity predicted by the Stokes' law and the flow velocity by taking their differences. Note that the diameter of the bubbles has some distribution, for example, $33 \sim 43 \mu \mathrm{m}$ at $-1 \mathrm{~mA}$, because Fig. 4 summarizes the rising velocities of all the bubbles at different distances from the electrode. First, we notice that the diameter of the bubbles tends to become smaller at the highe current, and the similar results have been reported earlier. ${ }^{19}$ Second, the rising velocity depends on not only the bubble diameter but also the current. At the lowest current we have employed, $-1 \mathrm{~mA}$, the rising velocity is well-described by the terminal velocity predicted by the Stokes' law, and this mean that the rising velocity is essentially determined by the buoyancy of the bubbles and the viscosity of the surrounding electrolyte. At the higher currents, however, deviation of the measured rising velocity from the theoretical one becomes more evident due to the presence of flow, as shown by arrows in Fig. 4: At the higher current the bubble formation occurs more frequently at the site, and this leads to the formation of vertically aligned bubbles with a smaller interval between them which generates the upward flow of the electrolyte_(movie S1 3 , ESI+). This way, even for the bubbles with a same diameter the rising velocity tends to become faster at the higher current. However, the Reynolds number associated with the bubble in liquid is as small as 0.06 in our case (Reynolds number, ESI + ), which suggests that the bubble dynamics are governed by the viscosity, and hence the flow may be neglected for the analysis.

In this work we have developed a new technique to optically and remotely detect hydrogen bubbles near the $\mathrm{Ni}$ wire electrode during the electrolysis under the constant-current mode, and using the diffusion model, obtained the concentration profile of the dissolved hydrogen gas as a function of distance from the electrode. Due to the technical difficulty, the spatial range we have successfully obtained the concentration profile of the dissolved hydrogen is about 15 170 um from the electrode, and accordingly, we have performed the linear extrapolation of the concentration profile toward the electrode surface. It turns out that the concentration of the dissolved hydrogen gas on the electrode is still much smalle than the value reported for a flat electrode. This discrepancy suggests that the electrode surface we have employed in this work cannot be approximated to be ideally flat. Our results have clearly revealed the presence of favourable sites on the electrode for the bubbles to form under the relatively low supersaturation, and we hope that our work stimulates the further studies to clarify the bubble forming mechanism on an electrode with a few hundred $\mathrm{nm}$ surface roughness as we have employed in this work, since it is of practical importance.

This work was supported by New Energy and Industrial Technology Development Organization (JPNP14021).

\section{Conflicts of Interest}

There are no conflicts to declare.

\section{Notes and references}

1 Z. Lu, W. Zhu, X. Yu, H. Zhang, Y. Li, X. Sun, X. Wang, H. Wang, J. Wang, J. Luo, X. Lei and L. Jiang, Adv. Mater., 2014, 26, 26832687

2 N. K. Chaudhari, H. Jin, B. Kim and K. Lee, Nanoscale, 2017, 9 , 12231-12247.

Q. Chen, H. S. Wiedenroth, S. R. German and H. S. White, J. Am. Chem. Soc., 2015, 137, 12064-12069.

4 S. R. German, M. A. Edwards, H. Ren and H. S. White, J. Am. Chem. Soc., 2018, 140, 4047-4053.

5 Y. A. Perez Sirkin, E. D. Gadea, D. A. Scherlis and V. Molinero, J. Am. Chem. Soc., 2019, 141, 10801-10811.

6 R. Hao, Y. Fan, M. D. Howard, J. C. Vaughan and B. Zhang, Proc Natl. Acad. Sci. U. S. A., 2018, 115, 5878-6588

7 S. H. Ahn, I. Choi, H. Y. Park, S. J. Hwang, S. J. Yoo, E. Cho, H. J. Kim, D. Henkensmeier, S. W. Nam, S. K. Kim and J. H. Jang, Chem. Commun., 2013, 49, 9323-9325.

8 J. P. Glas and J. W. Westwater, Int. J. Heat Mass Transf., 1964, 7 1427-1443.

9 H. Vogt, Electrochim. Acta, 1980, 25, 527-531.

10 P. Van Der Linde, Á. Moreno Soto, P. Peñas-López, J. RodríguezRodríguez, D. Lohse, H. Gardeniers, D. Van Der Meer and D. Fernández Rivas, Langmuir, 2017, 33, 12873-12886.

11 X. Zhao, H. Ren and L. Luo, Langmuir, 2019, 35, 5392-5408.

12 A. Battistel, C. R. Dennison, A. Lesch and H. H. Girault, J. Phys. Chem. C, 2019, 123, 10849-10856.

13 V. S. J. Craig, B. W. Ninham and R. M. Pashley, J. Phys. Chem., 1993, 97, 10192-10197.

14 X. Chen, A. Maljusch, R. A. Rincón, A. Battistel, A. S. Bandarenka and W. Schuhmann, Chem. Commun, 2014, 50, 13250-13253.

15 Y. Wang, E. Gordon and H. Ren, J. Phys. Chem. Lett., 2019, 10 3887-3892.

16 P. S. Epstein and M. S. Plesset, J. Chem. Phys., 1950, 18, 1505.

17 R. Fernández-Prini, J. L. Alvarez and A. H. Harvey, J. Phys. Chem. Ref. Data, 2003, 32, 903-916.

18 S. F. Jones, G. M. Evans and K. P. Galvin, Adv. Colloid Interface Sci., 1999, 80, 27-50.

19 P. Chandran, S. Bakshi and D. Chatterjee, Chem. Eng. Sci., 2015, 138, 99-109.
書式変更：フォントの色：青

書式変更：フォント：9 pt, 太字 (なし)

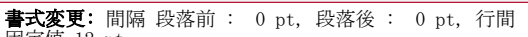

